\title{
Letters
}

Website: bmj.com

Email: letters@bmj.com

\section{Health care for asylum seekers}

\section{Main obstacles are inflexibility of NHS} and bureaucracy of support systems

EDITOR-Asylum seekers often receive poor health care, according to the Audit Commision. ${ }^{1}$ In east Kent we care for many resident asylum seekers and for many more who arrive at the Channel ports and move to accommodation in other parts of the country. Since February 1999 we have tried to meet the medical needs of people from 43 different countries. In our part of Kent there are no trained interpreters, and, indeed, to expect to have an interpreter on hand at a moment's notice for this number of languages is unrealistic. We have found that even commercial telephone translation services are not able to supply some of the languages we require. Despite this, we hope that we are not guilty of offering a poor service. Listening to patients, careful body language, and the use of diagrams and written material (some of which has been translated by the asylum seekers themselves) are all techniques that have enabled us to communicate to a reasonable level. It is not difficult to show that you are trying to help, and with encouragement people will often find ingenious ways of expressing themselves.

\section{Advice to authors}

We prefer to receive all responses electronically, sent either directly to our website or to the editorial office as email or on a disk. Processing your letter will be delayed unless it arrives in an electronic form.

We are now posting all direct submissions to our website within 24 hours of receipt and our intention is to post all other electronic submissions there as well. All responses will be eligible for publication in the paper journal.

Responses should be under 400 words and relate to articles published in the preceding month. They should include $\leqslant 5$ references, in the Vancouver style, including one to the BMJ article to which they relate. We welcome illustrations.

Please supply each author's current appointment and full address, and a phone or fax number or email address for the corresponding author. We ask authors to declare any competing interest. Please send a stamped addressed envelope if you would like to know whether your letter has been accepted or rejected.

Letters will be edited and may be shortened.

bmj.com

letters@bmj.com
The main obstacles to providing appropriate care are the inflexibility of the NHS and the delays and bureaucracy inherent in the arrangements for the support of asylum seekers. Many people arrive with no money at all, and it takes time for them to receive vouchers. In the meantime, how does a woman who is menstruating buy sanitary protection? How does a mother in bed and breakfast accommodation obtain nappies for her baby? How do they pay for prescriptions? An exemption certificate (HC2) comes as part of the support package for asylum seekers, but it can take up to three weeks to be issued.

In our experience, it is solving problems like these that consumes time and energy. General practitioners should be reassured that asylum seekers are resourceful and their needs are not overwhelming; neither are the language barriers insurmountable. What we do find overwhelming is the gratitude our patients show to us in response to our genuine efforts to understand their difficulties and be their advocates in dealing with systems that are cumbersome and often hostile.

Sarah Montgomery general practitioner

Guildhall Surgery, Folkestone CT20 1EJ

plefandsem@doctors.org.uk

Peter Le Feuvre general practitioner

Dover Health Centre, Dover CT16 1RH 1 Jones J. Asylum seekers receive poor health care. BMJ

\section{General practitioners' knowledge of} issues relating to asylum seekers is poor

EDITOR-Government policy to redistribute asylum seekers away from the London area will mean that they may be placed in the care of people without any specialist knowledge of their problems, including people working in primary care. Access to local health authority outreach services and special refugee community groups will be more difficult, which will increase feelings of isolation.

Although all asylum seekers are eligible for free NHS treatment and have the right to register with a general practitioner, general practitioners are often confused about these people's entitlements. ${ }^{1}$ They have been registered on a temporary rather than a permanent basis, thereby being excluded from a full package of checks and advice. ${ }^{2}$ Additionally, various forms of identification are being requested before registration.

A recent telephone survey of 50 general practitioners in the Sandwell region of the
West Midlands showed that 26 had asylum seekers registered with them. Sixteen had registered them as permanent residents and seven on a temporary basis; three had asylum seekers in both groups.

Thirty seven of the general practitioners said that, before registering asylum seekers, they would ask for some form of identification regarding their status. The document most often requested was a passport $(n=32)$. Other documents asked for included immigration papers $(n=8)$ and Home Office documents $(n=4)$. Some practices required more than one proof of identity

The general practitioners' knowledge about asylum seekers' entitlement to NHS treatment varied. Although 42 thought that asylum seekers were entitled to free treatment, four were not sure, two thought that they were not, and two thought that they were entitled to free treatment only if they came from member states of the European Union. Only two knew of any recent changes in legislation regarding asylum seekers.

Because of the redistribution of asylum seekers throughout Britain, many general practitioners will find themselves faced with new issues of care. In the absence of any national guidelines, each health authority must provide guidance for primary care groups for the integration of asylum seekers into general practices. This should emphasise that practices are not required to ask for passports or immigration documents as proof of status and should encourage general practitioners to offer permanent rather than temporary registration. These guidelines could be incorporated into a general information package, which could also provide information about social services, education, and interpreting services and a directory of telephone numbers of both local and national helplines.

Sumra Dar specialist registrar in public health and occupational health

Sandwell Health Authority, West Bromwich B70 9LD

sumradar@hotmail.com

1 Refugee Health Consortium. Promoting the health of refugees. London: RHC, 1998.

2 Jones D, Gill P. Refugees and primary care: tackling the inequalities. BMJ 1998;317:1444-6.

3 Grant C, Deane J. Stating the obvious-factors which influence the uptake and provision of primary care services to refugees. In: London: Brixton challenge. London: Lambeth, refugees. In: London: Brixtom challenge. London: La
Southwark and Lewisham Health Authority, 1995.

Germany has better method of dealing with asylum seekers' medical problems EDITOR-In June I started working in direct contact with asylum seekers and refugees. My current position in the north of Glasgow was created as a response to the dispersal 
policy mentioned by Connelly and Schweiger, ${ }^{1}$ so I am in a bad position to criticise the policy.

What does upset me, though, is the comparatively large number of patients arriving here who have ongoing, acute, and severe health problems-patients whom I would never have advised to undertake a house move or a long bus journey. They had been seen and registered by general practitioners in the south east of England, and treatment was started. Apparently, several patients even arrived with a letter from their general practitioner stating that a transfer was not appropriate at this stage; their treatment was interrupted, and it took time to re-establish contact with them.

I wonder whether the German model might be a better one. In Germany new arrivals are housed in camps for several weeks until an initial medical examination has been done and all acute problems have been sorted out. This includes updating vaccinations, carrying out tuberculosis screening, etc. As the camps are central points of arrival it also helps to re-establish contact with relatives lost during travel or at border crossings. Only after everything urgent has been sorted out do people get dispersed; they are then free to register with a general practitioner of their choice at their new destination.

The minimum requirement should be that people with acute problems do not get put on buses to be transported to far off places without their general practitioner having been asked if this is an advisable step.

Peter von Kaehne salaried general practitioner Springburn Health Centre, Glasgow G21 1TR vkaehne@doctors.org.uk

1 Connelly J, Schweiger M. The health risks of the UK's new asylum act. BMJ 2000;321:5-6. (1 July.)

\section{Use of ambulatory blood pressure monitoring}

Elegant new test needs clinical indication

EDITOR-O'Brien et al in their paper state that monitoring ambulatory blood pressure may be useful for diagnosing white coat hypertension, a diagnosis that should be considered before drugs are prescribed. ${ }^{1}$ But they do not give criteria that can be used to identify which patients with raised blood pressure should be selected for monitoring. This, perhaps, is not surprising since O'Brien et al admit that white coat hypertension has no clinical characteristics to help in diagnosis. We must therefore presume that they believe that all newly diagnosed patients with hypertension would benefit from ambulatory monitoring of blood pressure.

O'Brien et al make no claims that ambulatory monitoring is likely to improve the process of care when they state that the role of ambulatory measurement in guiding drug treatment has not been fully established. They seem to doubt the value of readings of ambulatory blood pressure when they say that deciding what constitutes normal blood pressure and what constitutes abnormal in ambulatory measurement is controversial. O'Brien et al do not say that monitoring ambulatory blood pressure improves a patient's prognosis.

So should doctors monitor ambulatory blood pressure in all patients with newly diagnosed hypertension to exclude patients with white coat hypertension? On the evidence provided, quite clearly the answer is no. Monitoring ambulatory blood pressure, like so many other tests, is yet another elegant new test in want of a clinical indication

A M Rouse senior lecturer

Department of Public Health and Epidemiology, University of Birmingham, Birmingham B15 2TT A.M.Rouse@bham.ac.uk

1 O'Brien E, Coats A, Owens P, Petrie J, Padfield PL, Little WA, de Swiet M, Mee F. Use and interpretation of ambulatory blood pressure monitoring: recommendations of the British Hypertension Society. BMJ 2000:320:1128-34 (22

\section{Author's reply}

EDITOR-Rouse is correct in his reading of our paper when he reiterates the clear message that white coat hypertension should be considered before prescribing blood pressure lowering drugs, which may not be necessary in many people who have a spurious rather than sustained rise in blood pressure. His interpretive ability does not fail him either when he concludes that a technique such as ambulatory blood pressure measurement is needed to diagnose white coat hypertension as there are no clinical characteristics to identify the condition. He then presumes that we believe that "all newly diagnosed hypertensive patients would benefit from ambulatory blood pressure monitoring." If ambulatory monitoring saves patients from unnecessary lifelong drug treatment it follows that they will benefit from the technique. Let me go further and say that I would seek another opinion if a doctor measured my blood pressure using the conventional technique and then proceeded to write me a prescription.

Rouse is also irritated by the fact that the recommendations acknowledge that the role of ambulatory measurement in guiding drug treatment has not yet been fully established and that there is controversy over the exact cut-off points for ambulatory blood pressure. These are statements of fact-we have been careful to indicate in our paper where there is uncertainty and doubt.

Rouse is incorrect when he says: "[we] do not say that ambulatory monitoring improves a patient's prognosis." In the introduction we state: "Although the results of a number of ongoing, longitudinal studies are forthcoming, there is now firm evidence that ambulatory blood pressure measurement is a more sensitive predictor of cardiovascular outcome than conventional measurement." We later say that the technique predicts outcome more accurately than conventiona measurement in white coat hypertension, elderly people, patients with nocturnal hypertension, and pregnancy.
Rouse's negative strictures remind me of another commentator of similar outlook, who, writing in 1895 on the newly introduced technique of sphygmomanometry, acknowledged that "the middle-aged and successful physician may slowly and imperceptibly lose the exquisite sensitiveness of his finger tips through repeated attacks of gouty neuritis" but was confident that the sphygmomanometer would not be welcomed by the "overworked and underpaid general practitioner, already loaded with thermometer, stethoscope, etc."

Eoin O'Brien professor of cardiovascular medicine Blood Pressure Unit, Beaumont Hospital, PO Box 1297, Dublin 9

eobrien@iol.ie

On behalf of the British Hypertension Society Working Party on Blood Pressure Measurement

1 Blake E. Recent British researches on arterial tension. Med Times Gaz 1895;23:29.

\section{The secret life of the NHS}

\section{Trust seems not to have understood} function of walk-in centre

EDITOR-Jones writes about "what the government of the day would rather you didn't know" and says that "NHS staff have been pressured by management and government representatives not to give interviews or make press statements critical of NHS services." This works both ways. Often NHS management and staff, knowing that they have a problem, don't want their immediate superiors, colleagues, the public, or the government to know-they themselves may not wish to acknowledge its exact nature.

The problem may be discussed off the record within "in-groups," which implicitly see public criticism as unacceptable and certainly won't go public with their views. This aspect of NHS culture has taken decades to evolve, and it is simplistic to attribute it solely to pressure from governments.

After much thought I have decided to violate my own cultural norms by publicising some problems at the Newcastle Westgate Primary Care Walk In Centre, which illustrate the gap between policy decisions and their implementation. This centre was intended to fulfil a need for accessible primary care in a deprived area with many social problems. It is staffed by experienced primary care nurse practitioners, but it is managed by an acute trust and is located within the accident and emergency department's minor injuries unit, adjacent to the intensive care unit. It is poorly signposted and is accessible down a corridor after triage by an accident and emergency nurse; it gives the impression of being an ill defined part of the accident and emergency department.

Written protocols were provided but are, to put it succinctly, useless. They are not evidence based and give inadequate information to inform management. In practice, they have covered only about half of the problems presented. The trust imposed a 
rule that the nurse practitioners were not to see children below the age of 2 years-and then advertised the centre with a picture of a nurse holding a baby. These nurse practitioners have been seeing infants for years; one is a qualified health visitor.

The trust seems not to have understood the function of the centre, the skills offered by the nurse practitioners, the nature of primary care, or the needs of the potential patients. Managers seem to have been too concerned to avoid threats (legal liability, criticism by senior management, or loss of control) to exploit opportunities (to develop a patient friendly, nurse led, primary care facility). A potentially valuable initiative has thereby been brought close to failure.

Toby Lipman general practitioner

Westerhope Medical Group, Westerhope, Newcastle upon Tyne NE5 2LH

toby@tobylipm.demon.co.uk

Dr Lipman is responsible for facilitating the nurse practitioners' ongoing education, and his practice is responsible for clinical support and mentoring.

1 Jones J. The secret life of the NHS. BMJ 2000;320:1457-9. (27 Mav.)

\section{Managers have invented new system for reducing waiting list times in Suffolk}

EDITOR-Jones has written about the secret life of the NHS. ${ }^{1}$ Responding to central pressure to decrease waiting times, the managers of the child psychiatric service in Suffolk have invented a wonderful system. Cases referred by general practitioners for a specialist opinion are declared ineligible for receiving any specialist service and are simply referred back to the general practitioner. Thus they disappear from waiting lists and don't exist. A few general practitioners have protested, but there has been not a word from the health authority. A small number of cases (maybe 10-20\%) get through on the basis of meeting stringent urgency criteria, but these exclude most treatable cases.

Kirk Weir consultant psychiatrist Woodbridge, Suffolk IP12 1LW

1 Jones J. The secret life of the NHS. BMJ 2000;320:1457-9. (27 May.)

**We are interested in hearing about examples of waiting list scams. If you know of other ploys being used in the United Kingdom please contact Judy Jones (judyjones@serneus.ssnet.co.uk).

\section{Predicting left ventricular systolic dysfunction}

\section{Combining test results gives best predictive effect}

EDITOR-Landray et al chose a cut-off level for brain natriuretic peptide of $17.9 \mathrm{pg} / \mathrm{ml}$. They said that other levels (10 or $76 \mathrm{pg} / \mathrm{ml}$ ) did not improve the predictive characteristics. However, this level correctly predicted left ventricular systolic dysfuntion in only 64 of 126 patients. A level of $76 \mathrm{pg} / \mathrm{ml}$ correctly
B-scores for predictors of left ventricular systolic dysfunction

\begin{tabular}{lcc} 
Predictor & Presence & Absence \\
\hline Past myocardial infarction & +4 & -1 \\
\hline Abnormal electrocardiogram & +3 & -1 \\
\hline Abnormal chest radiograph & +1 & -1 \\
\hline $\begin{array}{l}\text { Brain natriuretic peptide level } \\
>76 \mathrm{pg} / \mathrm{ml}\end{array}$ & +5 & -3 \\
\hline
\end{tabular}

predicted 111 cases out of 126 (calculated from the sensitivity and specificity figures) and is therefore clearly superior. This proportion is similar to that found by Smith et al for a cut-off level of $26.7 \mathrm{pmol} / \mathrm{l} .{ }^{2}$ Both these levels are about two to three times the median level of the normal population.

The other screening tests assessed by Landray et al are likely to be independent predictors, as they are proxies for different aspects of heart failure and have been shown by Nielsen et al, using multiple logistic regression, to be statistically independent. ${ }^{3}$ It would therefore be possible to combine the predictive effect of these tests using bayesian analysis. The B-score method $^{45}$ can be used to calculate bayesian scores from Landray et al's data, giving scores for presence or absence of each item of the data (table). The prior probability score is for a $32 \%$ prevalence of heart failure in patients referred by the general practitioners in the study. A prospective study would be needed to test this predictive method. The method of using the scores is to add the score for presence or absence of each data item. It is acceptable to omit any data items-for example, natriuretic peptide - not available at the time, as data items are independent predictors. The total score corresponds to the posterior odds ratio as follows: +2 equates to 2 to 1 in favour of heart failure; -2 equates to 2 to 1 against. The odds double for each increase of 2 , so +4 equates to 4 to 1 in favour, +6 to 8 to 1 in favour, and so on.

Frank Dobbs senior lecturer

Department of Primary Health Care and General Practice, University of Plymouth, Plymouth PL6 8BX

fdobbs@plymouth.ac.uk

1 Landray MJ, Lehman R, Arnold I. Measuring brain natriuretic peptide in suspected left ventricular systolic dysfunction in general practice: cross-sectional study. $B M J$ 2000;320:985-6. (8 April.)

2 Smith H, Pickering RM, Struthers A, Simpson I, Mant D. Biochemical diagnosis of ventricular dysfunction in elderly patients in general practice: observational study. BMJ patients in gen

3 Nielsen OW, Hansen JF, Hilden J, Larsen CT, Svanegaard J Risk assessment of left ventricular systolic dysfunction in primary care: cross sectional study evaluating a range of diagnostic tests. BMJ 2000;320:220-4

4 Dobbs FF, Fleming DM. A simple scoring system for evaluating symptoms, history and urine dipstick testing in diagnosis of urinary tract infection. $J R$ Coll Gen Prac 1987;37:100-4

5 Dobbs F. A scoring system for predicting group A streptococcal throat infection. BrJ Gen Pract 1996;46:461-4.

\section{Cut-off level was inappropriate}

EDITOR-The level of brain natriuretic peptide varies continuously over a huge range, which means that the effectiveness of different cut-off values varies. Most authorities now use the level that gives a sensitivity $\geqslant 95 \%$, as the role of the test is to rule out systolic dysfunction, not rule it in. (Incidentally, the Shionogi brain natriuretic peptide assay produces different absolute values from most other assays, so using a cut-off level of $17.9 \mathrm{pg} / \mathrm{ml}$ in a Shionogi assay is probably inappropriate.) This wide range of brain natriuretic peptide values contrasts with more readily available tests-previous myocardial infarction, an abnormal electrocardiogram, or an abnormal chest radiograph-which give only the categorical results of normal or abnormal.

A reanalysis of Landray et al's results using the brain natriuretic peptide value that gives $\geqslant 95 \%$ sensitivity would be interesting. ${ }^{1}$ This would show that this cut-off value improves the posterior probability of the disease in comparison with the categorical variables of screening by past myocardial infarction or abnormal electrocardiogram or chest radiograph. The performance characteristics that Landray et al describe may well be due simply to their having used an inappropriate cut-off value.

Allan D Struthers professor

Ninewells Hospital and Medical School, Dundee DD1 9SY

a.d.struthers@dundee.ac.uk

1 Landray MJ, Lehman R, Arnold I. Measuring brain natriuretic peptide in suspected left ventricular systolic dysfuncretic peptide in suspected left ventricular systolic dysfunction in general practice: cross-sectional study. BMJ

\section{Authors' reply}

EDITOR-Our study was a pragmatic attempt to test a model of service provision that would allow general practitioners to provide evidence based treatment for patients with impaired left systolic function. All major therapeutic trials in heart failure have selected patients by measuring left systolic ejection fraction, using a variety of methods and cut-off points. In routine clinical practice, a single qualitative estimation at rest, using transthoracic echocardiography, is almost always the criterion for deciding treatment. This is not a "gold standard" for heart failure but simply a proxy measure for identifying patients who might benefit from treatment with an angiotensin converting enzyme inhibitor, in line with the evidence from large scale, randomised controlled trials.

Plasma concentrations of brain natriuretic peptide show a strong correlation with echocardiographic and other measures of impaired systolic function. We are left with the dilemma of choosing arbitrary cut-off points for many diagnostic tests. Dobbs is right to say that choosing a high cut-off level, such as $76 \mathrm{pg} / \mathrm{ml}$, gives the best overall predictive results. However, if the point of the test is to rule out systolic dysfunction rather than to rule it in, as Struthers observes, sensitivity rather than overall predictive value is the key consideration. As we indicated, a cutoff level of $10 \mathrm{pg} / \mathrm{ml}$ would increase the sensitivity to $92 \%$ but only at the expense of including $87 \%$ of patients without systolic dysfunction on echocardiography. ${ }^{1}$ As Struthers points out, this problem of balance is worse in the case of brain natriuretic peptide 
because of the different values obtained by different biochemical assay techniques, to which one might add the different units commonly used $(\mathrm{pg} / \mathrm{ml}$ or $\mathrm{pmol} / \mathrm{l})$. Other similar studies included fewer cases than ours, yet further refinement of the acceptable cut-off level for concentration would require studies of at least several hundred cases. There have been calls for simple, large scale studies of diagnostic procedures, including clinical examination, ${ }^{2}$ which would clearly benefit from such an approach. As the appropriate cut-off level has not yet been properly identified, we stand by our conclusion that there is insufficient evidence to support the routine use of plasma concentrations of brain natriuretic peptide as a screening test for heart failure.

Martin J Landray lecturer in medicine

University of Birmingham, Birmingham B15 2TH m.j.landray@bham.ac.uk

Richard Lehman general practitioner

Hightown Surgery, Banbury OX16 9DB

Ian Arnold consultant cardiologist

Horton Hospital, Oxford Radcliffe Hospitals

NHS Trust, Banbury OX16 9AL

1 Landray MJ, Lehman R, Arnold I. Measuring brain natriuretic peptide in suspected left ventricular systolic dysfunction in general practice: cross-sectional study. $B M J$ tion in general practice:

2 McAlister FA, Straus SE, Sackett DL. Why we need large, McAlister FA, Straus SE, Sackett DL. Why we need large,
simple studies of the clinical examination: the problem and a proposed solution. Lancet 2000;354:1721-4.

\section{Randomised controlled trial of chest pain units is needed}

EDITOR-Collinson et al audited prognostically important myocardial damage in patients discharged from the emergency department-a large and important healthcare problem. ${ }^{1}$ The commentary by Kennedy touches on several key issues as well as the obvious limitations of such a study. As Kennedy says, further follow up data on the seven patients with raised concentrations of troponin would be useful.

Kennedy also touched on the issue of definitions. The seven missed Mayday patients had myocardial damage but would not satisfy the definitions of acute myocardial infarction held by the World Health Organization or the monitoring trends and determinants in cardiovascular disease (MONICA) study. Collinson et al are, however, correct to point out that such patients have a less favourable prognosis. Should these classic definitions be reconsidered? The $6 \%$ of discharged patients with troponin $\mathrm{T}$ concentrations above $0.1 \mathrm{ng} / \mathrm{ml}$ have a substantial short term mortality and morbidity, ${ }^{2}$ yet this can be improved by treatment. ${ }^{3}$ Discharge of such patients should be avoided, even if they fail to meet classic definitions of acute myocardial infarction.

Chest pain observation units may prevent these inappropriate discharges. One such unit has been operational in the accident and emergency department of the Northern General Hospital in Sheffield since March 1999. Similar follow up has been used to monitor those discharged (electrocardio- graphy and troponin $\mathrm{T}$ concentration 72 hours after attendance). So far 761 patients have been assessed on the unit, of whom $86 \%$ were successfully discharged; $580(88 \%)$ of those discharged attended follow up. Only one patient had a concentration of troponin $\mathrm{T}>0.1 \mathrm{ng} / \mathrm{ml}(0.17 \%)$. Using the recommended audit tool of Collinson et al in this way suggests that the Sheffield chest pain observation unit performs well. However, longer term follow up data need to be collected, and, ultimately, only a randomised controlled trial can tell us whether the chest pain observation unit is superior to routine care.

A recent systematic review has examined the efficacy of chest pain observation units and their apparent cost effectiveness, but most data come from the United States. We believe that there is an urgent need for a randomised controlled trial in the very different circumstances of the British NHS.

Steve Goodacre research fellow

steveg@doctors.org.uk

Francis Morris consultant in accident and emergency medicine

Department of Accident and Emergency Medicine, Northern General Hospital, Sheffield S5 7AU

Simon Capewell professor of clinical epidemiology

Department of Public Health, University of Liverpool, Liverpool L69 3GB

1 Collinson PO. Premachandram S, Hashemi K. Prospective audit of incidents of prognostically important myocardia damage in patients discharged from the emergenc department [with commentary by R Lee Kennedy]. $B M$ 2000:320:1702-5. (24 June.)

2 Capewell S, McMurray JJV. "Chest pain-please admit:" is there an alternative? $B M J$ 2000;320:951-2. (8 April.)

3 Lindahl B, Venge P, Wallentin L, for the FRISC study group. Troponin T identifies patients with unstable coronary artery disease who benefit from long-term antithrombotic protection. J Am Coll Cardiol 1997;29:43-8.

Goodacre SW Should we establish chest pain observation units in the United Kine stabish chest pain observation Emerg

Emerg Med 2000;17:1-6.

JA A desip, UK hospital [abstract]. J Accid Emerg Med 2000;17:58.

\section{Societal cost-benefit analysis of teledermatology}

\section{Costs were understated}

Editor-The article by Wootton et al is a valuable addition to the limited literature on the cost effectiveness of telemedicine applications. $^{1}$ But we have some reservations about their calculations of the net societal cost of a teledermatology consultation.

Wootton et al are comparing outpatient dermatology, current clinical practice, with real time teledermatology in terms of clinical outcomes, cost benefit (which should theoretically include the monetary valuation of clinical outcomes), and patient satisfaction.

Having calculated a total cost of $£ 201.88$ for a teledermatology consultation, Wootton et al subtracted two values from this total to arrive at the net societal cost. Firstly, they deducted the "savings" that would be made from reduced dermatology referrals, which they attribute to the learning benefits and increased confidence in managing patients obtained from the joint videolink consultation.
Our point of contention is that they were wrong to subtract a further $£ 69.78$ for the "benefits" of the programme. These "benefits" do not reflect clinical outcomes, as Wootton et al found no major differences in the two approaches in terms of clinical outcomes. Rather it is an imputed measure of the training cost necessary to achieve the same educational impact as the experience obtained using telemedicine. This would, presumably, lead to a similar reduction in dermatology referrals as achieved by telemedicine. This then begs the question of who exactly in society would actually benefit to the tune of $£ 69.78$, as this training is not currently provided in current clinical practice.

This result, as presented in the paper, seems to be a form of double counting. Real time teledermatology may or may not be cost effective, but its societal benefits surely cannot include the savings from reduced referrals and the cost of training necessary to obtain a similar pattern of referrals from general practice in the absence of telemedicine.

Paul Jacklin research fellow paul.jacklin@lshtm.ac.uk

Jenny Roberts reader in economics and public health Department of Public Health Policy, London School of Hygiene and Tropical Medicine, London WC1E 7HT

1 Wootton R. Bloomer SE, Corbett R, Eedy DJ, Hicks N, Lotery HE, et al. Multicentre randomised control tria comparing real time teledermatology with conventional outpatient dermatological care: societal cost-benefit analysis. BMJ 2000;320:1252-6. (6 May.)

\section{Authors' reply}

EDITOR-Jacklin queries the rationale for showing the value of the knowledge transfer as a benefit to society. Transfer of knowledge from the expert who is consulted to the person who is making the consultation is commonly said to occur in large real time telemedicine programmes. It is also widely acknowledged as being very difficult to quantify.

As stated in our paper, there are a number of additional benefits from teledermatology, such as the psychological impact on patients and their avoiding paying for interim treatments while waiting for a specialist appointment. The general practitioners in the trial also mentioned increased job satisfaction. These are all difficult to measure, and we omitted them from the analysis.

The general practitioners also mentioned gaining considerable benefits from the learning effect in terms of managing their own and their colleagues' patients. The general practitioners estimated the value of the knowledge they had gained during the project as being of equivalent worth to attending a certain number of study days-a one off benefit that they had gained as a result of participating in regular teledermatology consultations. This is not double counting because the knowledge gained was used by the general practitioners for the management of all their dermatology patients, not just the 5\% who would normally have been referred for hospital treatment. The knowledge transfer (assum- 
ing that the general practitioners estimated it correctly) was simply an additional benefit for the general practitioners that they would not otherwise have received; if it was overestimated in our study, then the magnitude would be of the order of 100/95.

The original economic analysis was done by a well known British economics consultancy. Since Jacklin raised the point we have consulted two independent academic health economists in different countries outside the United Kingdom. One disagreed with Jacklin's point entirely, and one partially. From the remarks they made it is clear that there is scope for debate about what benefits should be included and how. Economics does not seem to be an exact science in this respect, which is a pity.

Richard Wootton professor of online health r.wootton@pobox.com

Maria Loane senior research officer Centre for Online Health, Royal Brisbane Hospital, Herston 4029, Australia

\section{Life is as much a pain as it ever was}

EDITOR-The article by Palmer et al shows that the reporting of back pain in the United Kingdom has increased during the past decade. ${ }^{1}$ This is potentially important because, despite rises in indirect measures such as sickness and invalidity benefit payments for back pain in the United Kingdom and elsewhere, there has been little evidence that back pain is actually becoming more common. $^{2}$

We conducted two population pain studies in the same areas of northwest England at an interval of seven years. The methods used in the first study have been described in detail previously. It was conducted in 1991 in a random sample of subjects aged 18-80 years selected from the age-sex register of local general practices. Subjects received a postal questionnaire, with further mailings to non-responders. The area of survey and the methods used were identical in the second study, which was conducted during $1998 .{ }^{4}$ The participation rates were $75 \% \quad(\mathrm{n}=2342)$ and $84 \%$ $(\mathrm{n}=3417)$ respectively. In both studies subjects were asked: "During the past month, have you had any ache or pain which lasted for a day or longer?" Those who

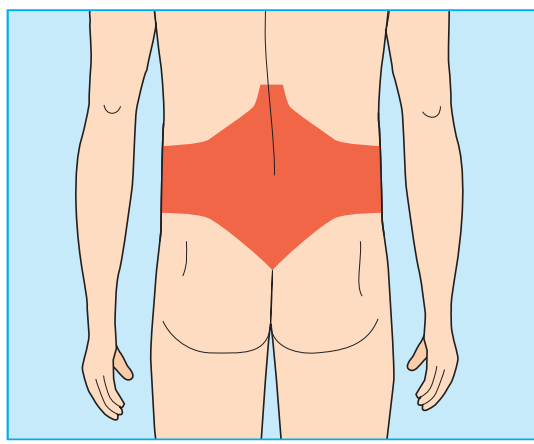

Area defined as low back in studies ${ }^{34}$ responded positively were asked to shade the area of pain on blank body manikins. The low back was thereafter defined as in the figure.

In the 1991 study the crude prevalence of low back pain was $26.1 \%$, whereas in the 1998 study the prevalence was slightly lower at $22.6 \%$ (difference $-3.5 \%, 95 \%$ confidence interval $-1.2 \%$ to $-5.8 \%$ ). Examination of rates specific to age and sex showed that no group had a marked increase in reporting.

Both this study and that of Palmer et al have been conducted on large populations and use similar methods in the studies between which comparisons are made, but they come to different conclusions on whether the reporting of back pain has become more common. They show the difficulties in examining time trends in back pain, where even small differences in methods can influence the resulting prevalences. But irrespective of whether back pain is now more common or not, Palmer et al are correct in their assertion that the solution to the current economic burden of back pain is most likely to lie in modifying people's attitudes and responses to symptoms.

Gary J Macfarlane professor of epidemiology Unit of Chronic Disease Epidemiology, School of Epidemiology and Health Sciences, The Medical School, University of Manchester, Manchester M13 9PT

John McBeth research associate

Adam Garrow research assistant

Alan J Silman professor of rheumatic disease epidemiology

Agricultural Research Council Epidemiology Unit, School of Epidemiology and Health Sciences, The Medical School, University of Manchester, Manchester M13 9PT

\footnotetext{
1 Palmer KY, Walsh K, Bendall H, Cooper C, Coggan D. Back pain in Britain: comparison of two prevalence surveys at an interval of 10 years. BMJ 2000;320:1577-8. (10 June.)

2 Croft P. Is life becoming more of a pain? $B M$ 2000;320:1552-3. (10 June)

3 Croft PR, Rigby AS, Boswell R, Schollum J, Silman A. The prevalence of chronic widespread pain in the aen in the general 93;20:710-3.

Papageorgiou AC, Silman AJ, Thomas E, Jayson MIV, Macfarlane GJ. The Cheshire foot pain and disability survey. Rheumatology 2000;39:S76.
}

\section{Paying for the NHS}

\section{Democratic control should not be dismissed}

EDITOR-The editorial by Mossialos et al on the funding of the NHS effectively dismisses the false panaceas of private or state insurance. ${ }^{1}$ But their arguments against hypothecation are less convincing.

Firstly, the comparative power of Britain's Treasury is set to decrease anyway, under the influence of British devolution and the growing power of the EU.

Secondly, if hypothecation were to increase the demand for expenditure on the NHS, is that necessarily a bad development?

Thirdly, it does not necessarily follow that increased expenditure on the NHS will reduce that on other (more beneficial) areas of public expenditure, such as transport and the environment
Finally, it is not clear why hypothecated tax should be more vulnerable to economic fluctuations than is the current system.

The core issue here is one of democratic control, informed by "grown up" debate. Discussion in the United Kingdom on the future of the NHS seldom rises beyond the level of the nursery because politicians have not trusted the public with adult choices. Allowing the electorate to have a more direct say over how their taxes are spentwhether by hypothecation, referendums, or other methods-is a bit scary for control freaks and somehow seems "un-British." But the experience of the past few years has shown that there is really no alternative. People will continue to moan about the NHS when they are excluded from any real decisions about it, and those who can afford to do so will eventually vote with their feet and take out private insurance, thereby creating a two tier service by default.

Arguably the greatest change introduced by this government has been to devolve some of its power to Scotland and Wales. It should now keep faith with the electorate and trust people throughout the United Kingdom to make some of the big choices for themselves. In this way, we can achieve an element of the discipline of the market-allowing people to choose what to buy-while retaining social justice.

Marcus Longley associate director

Welsh Institute for Health and Social Care, University of Glamorgan, Pontypridd CF37 1DL mlongley@glam.ac.uk

1 Mossialos E, Dixon A, McKee M. Paying for the NHS. BMJ 2000;320:197-8. (22 January.)

\section{Author's reply}

Editor-Longley's points on hypothecation are largely entirely true and, no doubt, would be accepted by the government were the relative powers of the Treasury and Department of Health to be reversed. We see no evidence that this is likely to happen. Hypothecation would bring some benefits to the health department but, as Longley notes, would severely weaken the power of the Treasury.

We do, however, take issue with his comments about the economic cycle hitting both hypothecated and general taxes equally. Tax revenues can fluctuate quite markedly over the cycle, especially where they are derived from direct taxation rather than, as with the overall tax take, from an increasingly wide range of sources. If the NHS was dependent on a fixed proportion of direct taxation there would be no scope to protect it at the expense of, say, expenditure on defence. It would thus be more vulnerable over the cycle.

The point about devolution is interesting and raises issues that are extremely poorly understood. The United Kingdom, unlike federal or confederate states, does not have any formal devolution of sovereign powers to its constituent parts. In Germany, for example, the federal government is prevented by the constitution from instructing the Länder (state) governments on what do in certain areas, such as many aspects of 
health policy. Although, formally, responsibility for certain matters has been devolved to the Scottish, Welsh, and Northern Irish assemblies, this is always subject to the power of Westminster to overrule them where their decisions might clash with British policy as a whole. It will be interesting, for example, to see the nature of the debate over the forthcoming Scottish Freedom of Information bill.

Some of these issues are already emerging in relation to university fees. Consequently it is important not to overestimate the impact of devolution.

Martin McKee professor of European public health ECOHOST, London School of Hygiene and Tropical Medicine, London WC1E 7HT martin.mckee@lshtm.ac.uk

\section{What about health needs?}

Editor-We read with disquiet the editorial by Mossialos et al, which explains how economists approach funding the NHS. ${ }^{1}$ They say that the United Kingdom faces three separate issues-how much money does it need to run a health service that is at least comparable to that in neighbouring countries; what should the health service spend the money on; and how should the money be collected? Their conclusion is that it is more important to answer the first question than the last.

We believe that the second question is the most important. Although we agree that incremental increases in NHS funding are likely to improve healthcare provision, this is far from certain. Disparities in funding levels between the countries of the United Kingdom do not seem to have a direct effect on health outcomes. ${ }^{2}$ It is important first to determine an ethical framework for allocation of resources among competing priorities in public health. Failure to do so will negate the government's commitment to improved participation of patients and the public in defining health needs and will instead serve to reinforce the primacy of the acute sector over population based approaches to health gain. As to the method of funding, the only system that is consistent with the principles on which the NHS was founded and is the least expensive to administer is progressive direct taxation, whether hypothecated or not.

Tony Baxter consultant in public health medicine Tony.Baxter@barnsley-ha.nhs.uk

Greg Connor specialist registrar in public health medicine

John Culver public health specialist trainee Barnsley Health Authority, Barnsley, South Yorkshire S75 2PY

1 Mossialos E, Dixon A, McKee M. Paying for the NHS. BMJ 2000;320:197-8. (22 January.)

2 Dixon J, Inglis S, Klein R. Is the English NHS underfunded? BMJ 1999;318:522-6.

\section{Spending should be decided by public and politicians}

EDITOR-In their editorial on financing the NHS Mossaiolos et al ask how to pay for the health service and how the funding is collected, but they omitted another important question: how should the money be spent?
Current expenditure on "health" is done in a disproportionate manner. The "health service" spends most of its money on the management of disease. Professionals with titles such as "reader in child health" are disease specialists. It is logical and obvious that more money should be concentrated on preventing disease. Politicians have said that this is important, but I have not heard them assert that they will allocate more money to prevent disease; under $5 \%$ of the United Kingdom's medical research budget is spent on researching the genesis of disease.

Holgate, in his article on allergic disorders, lists among his predicted developments the identification of the principal environment factors underlying the rising trends in allergic diseases to enable preventive strategies to be implemented. ${ }^{2}$ Researchers complain about lack of money, as do experts in other occupations. The amount spent in the United Kingdom on medical research is less than that spent by a successful industrial firm with a long term vision. Obtaining money for a research trial that tests if a manoeuvre will reduce the incidence of a disease is more difficult than raising funds for projects to accrue knowledge. Yet a controlled trial of disease prevention may show the mechanisms of disease genesis. Pharmaceutical firms, which may fund pure research, will not usually support disease prevention trials. Also, if the project crosses the boundaries of several disciplines-for example, applying molecular biology to a trial to reduce the incidence of a disease-it is more difficult to raise the money. A long time is needed to prove that a manipulation is effective even in common diseases. When an application for such a grant is sent to a charitable British funding source this causes difficulty for the management-namely, in deciding what is its field. This is required for the hierarchical management systems that devolve judgment to expert committees. The trial may not be funded because the wrong component is chosen as the focus for assessment; individually, this may be judged "not worthy enough" and the project rejected. If it was viewed in entirety on value and probity, it might have been accepted.

The potential value to the public should be included in appraisal. Spending should be decided by the public and politicians, with generalists providing an overview and specialists giving scientific appraisals.

Fleming Carswell reader in clinical experimental allergy and immunology

Department of Pathology and Microbiology, School of Medical Sciences, University of Bristol, Bristol BS8 1TD

1 Mossialos E, Dixon A, McKee M. Paying for the NHS. BM 2000;320:197-8. (22 January.)

2 Holgate S. Science, medicine, and the future: Allergic disorders. BMJ 2000;320:231-4. (22 January.)

\section{People covered by private health} insurance will not reduce consumption of NHS services

EDIToR-Dykes, in his rapid response to the editorial by Mossaiolos et al on funding the NHS, ${ }^{1}$ is right to point out the potential value to debate of assessing the balance of advantage from giving tax relief for health insurance premiums, ${ }^{2}$ especially since the figures needed for an outline estimate are on the internet and in the public domain.

We may start with two simplifying assumptions-that all private medical treatments would otherwise have been equivalently required to have been provided by the NHS, and that people covered by insurance do not increase their consumption of NHS services not covered by their policies.

Then we strip out from premiums the overhead and administrative costs and the profits of the insurance companies. In 1997 the British insurance industry paid $79 \%$ of premium income in claims (Association of British Insurers, www.abi.org.uk), but, at this rate, insurers were incurring serious losses, and a long term claims proportion of $75 \%$ is more realistic

We should strip out the equivalent overhead costs and non-treatment extras (single rooms, etc) from provider prices. The best way to do this is to match published tariffs for private procedures, including consultants' fees, ${ }^{3}$ with equivalent average figures in the published schedule of reference costs. ${ }^{4} \mathrm{~A}$ cataract extraction and lens prosthesis, which would be priced at $£ 1950-£ 2600$ when charged against health insurance, would cost the NHS £847; and a hip replacement, charged to an insurer at $£ 5800-£ 7500$, would cost the NHS $£ 3678$.

Having reviewed all the top dozen private procedures ${ }^{45} \mathrm{I}$ can state as a general rule of thumb that the reported average NHS cost is consistently around half the private insurance tariff.

It follows that $£ 1$ of premium income may be expected to permit some 75p in treatment claims, and this would equate to around $37 \mathrm{p}$ in NHS costs. Hence, although there is a margin for debate around specific figures, it may be safely concluded that, if tax relief were to be allowed at the higher rate of income tax (40p), the British Treasury would invariably lose.

Whether there might be a case for offering a restricted rate of tax relief would depend on how far our two initial simplifying assumptions may be contradicted in practice. Unfortunately, the evidence is not hopeful-there is little direct evidence that people who are covered by private health insurance are disposed to reduce their consumption of NHS services, nor is there any reason why they should. It is highly likely that their consumption of some NHS services-for example, consultations with their general practitioner-will increase.

Tom Hennell strategic analyst, NHS Executive

North West

Manchester M20 1JA

tom.hennell@virgin.ne

This letter expresses personal opinions and not the policy of the NHS Executive.

1 Mossialos E, Dixon A, McKee M. Paying for the NHS. BMJ 2000;320:197-8. (22 January.)

2 Dykes P. Paying for the NHS. Rapid response to Mossialos E, Dixon A, McKee M. Paying for the NHS. bmj.com 2000;320 (www.bmj.com/cgi/eletters/320/7229/197\#EL6).

3 Nuffield Hospitals. Private healthcare with Nuffield Hospitals (available at wring 
4 NHS Executive. The new NHS-reference costs (available at www.doh.gov.uk/nhsexec/refcosts/1998.htm)

5 BUPA. Fixed price care (available at www.bupa.co.uk/ fixed_price_care).

\section{Minimising harm from hepatitis $\mathrm{C}$ virus needs better strategies}

EDITOR-Hepatitis C virus and HIV are both blood borne, and infection may occur in injecting drug users, transmitted by sharing contaminated needles and syringes. Despite extensive harm reduction programmes in Australia, hepatitis $\mathrm{C}$ virus continues to spread among injecting drug users, but HIV does not, partly because the prevalence of hepatitis $\mathrm{C}$ virus has been high among injecting drug users in Australia since at least 1971, whereas that of HIV, present only from around 1982, has remained low.

Hepatitis $\mathrm{C}$ virus has a higher average transmission efficiency than HIV. It may be transmitted between injecting drug users on equipment other than needles and syringes. ${ }^{3}$ Injecting drug users in Australia commonly share other equipment-for example, swabs, spoons, filters, water, and tourniquets.

We studied used injecting equipment from 10 injecting settings for the presence of hepatitis C virus RNA, with one to four injecting drug users at each setting, at least one of whom was known to be positive for hepatitis $\mathrm{C}$ as shown by the results of a polymerase chain reaction. All used injecting equipment was collected and transported immediately to the laboratory. Hepatitis G virus RNA was isolated and purified from equipment using reagents in the QIAGEN QIAamp Viral RNA kit (QIAGEN, Australia).

Needles and syringes were flushed with the QIAGEN lysis buffer, spoons and swabs were rinsed or vortexed in lysis buffer, and water was processed as for serum in the manufacturer's protocol. All samples were tested for hepatitis $\mathrm{C}$ virus RNA with the AMPLICOR hepatitis $\mathrm{C}$ virus test (Roche Diagnostic Systems, Branchburg, NJ).

Hepatitis $\mathrm{C}$ virus RNA was detected on $70 \%(14 / 20)$ of syringes, $67 \%(6 / 9)$ of swabs, $40 \%(2 / 5)$ of filters, $25 \%(1 / 4)$ of spoons, and $33 \%(1 / 3)$ of water samples.

These findings imply that hepatitis $\mathrm{C}$ virus could be transmitted among injecting drug users on injecting equipment other than needles and syringes; evidence from behavioural studies suggests that such transmission may not be uncommon. ${ }^{3}{ }^{4}$ The public health message used in these groups for control of HIV transmission-not to share needles and syringes-may therefore be inadequate for control of hepatitis $\mathrm{C}$ virus, and other strategies must be canvassed, such as encouraging injecting drug users to use their drugs in ways other than injecting; more intense concentration on hygiene practices including handwashing; and education and support of injecting drug users to avoid sharing any equipment associated with injecting. A serious commitment to new and expanded harm minimisation strategies will be needed to reduce the continual spread of hepatitis $\mathrm{C}$ virus among injecting drug users, along with the growing toll of illness and cost. ${ }^{5}$

Nick Crofts head

Epidemiology and Social Research Unit, Macfarlane Burnet Centre for Medical Research, PO Box 254, Fairfield, Victoria 3078, Australia crofts@burnet.edu.au

Sonia Caruana research assistant

Scott Bowden molecular microbiologist

Victorian Infectious Diseases Reference

Laboratory, Locked Bag 815, Carlton South,

Victoria 3053, Australia

Michael Kerger outreach worker

Centre for Harm Reduction/Macfarlane Burnet

Centre for Medical Research, Footscray,

Victoria 3011, Australia

1 Crofts N, Aitken CK, Kaldor JM. The force of numbers: why hepatitis $\mathrm{C}$ is spreading among Australian injectin drug users while HIV is not. Med J Aust 1999;170:220-1.

2 Patz JA, Jodrey D. Occupational health in surgery: risks extend beyond the operating room. Aust NZ J Sur 1995;65:627-9

3 Van Beek I, Dwyer R, Dore GJ, Luo K, Kaldor JM. Infection with HIV and hepatitis $\mathrm{C}$ virus among injecting drug users in a prevention setting: retrospective cohort study. BMJ in a prevention set

4 Crofts N, Aitken CK. Incidence of bloodborne virus infec4 Crofts N, Aitken CK. Incidence of bloodborne virus infec-
tion and risk behaviours in a cohort of injecting drug users in Victoria, 1990-1995. Med J Aust 1997;167:17-20.

5 Coutinho RA. HIV and hepatitis C among injecting drug 5 Coutinho RA. HIV and hepatitis $\mathrm{C}$ among injecting drug
users-success in preventing HIV has not been mirrored users-success in preventing HIV has
for hepatitis C. BMJ 1998;317:424-5.

\section{Combination treatment for hepatitis $\mathrm{C}$ is not being given}

EDITOR-Current estimates suggest that up to $0.7 \%$ (400 000 individuals) of the population of the United Kingdom are infected with the hepatitis $\mathrm{C}$ virus. ${ }^{1}$ In some (roughly $30 \%$ ) of these people the virus causes a progressive hepatitis that leads to cirrhosis and cancer. ${ }^{2}$ European guidelines recommend that patients with progressive hepatitis $\mathrm{C}$ are treated with interferon and ribavirin. ${ }^{3}$ This cures $40 \%{ }^{4}$ and leads to an improvement in liver histology and a reduction in morbidity and liver cancer.

Although expensive, treatment for hepatitis $\mathrm{C}$ is cost effective as it reduces the need for liver transplantation. Anecdotal evidence suggests that in the United Kingdom combination treatment is not available to many patients because of restrictions imposed by purchasing authorities.

To determine if this is the case we conducted a postal survey among clinicians (447 members of the British Association for the Study of the Liver) who had an interest in the treatment of viral liver disease. Usable replies were received from 80 and reflected the views of 68 purchaser areas $(55 \%$ of the purchasers in the United Kingdom). The results (table) show that adequate funding for interferon and ribavirin is available in only a minority of health districts and that postcode prescribing occurs in the management of patients with this premalignant, treatable disease.

John Denham, minister of state at the Department of Health, has stated in parliament that "The fact that NICE [the National Institute for Clinical Excellence] is
Response to questionnaire regarding availability of funding for treatment of chronic infection with hepatitis C virus from clinicians representing 68 purchaser areas

No of

What is the policy of your health authority regarding the treatment of infection with hepatitis C virus?

\begin{tabular}{lr}
\hline Treat as per European guidelines & 4 \\
\hline Treat up to agreed funding level & 12 \\
\hline $\begin{array}{l}\text { Restricted funding (interferon only or } \\
\text { insufficient funding) }\end{array}$ & 3 \\
\hline Policy awaited & 6 \\
\hline No funding or no reply & 39 \\
\hline Is the policy to be reviewed soon? & 21 \\
\hline Yes & 11 \\
\hline No & 36 \\
\hline No reply & 21 \\
\hline Do you have a drugs budget for combination treatment? \\
\hline Yes & 42 \\
\hline No & 5 \\
\hline No reply & 17 \\
\hline Is the drugs budget sufficient? & 40 \\
\hline Yes & 11 \\
\hline No & \\
\hline No reply & \\
\hline
\end{tabular}

considering combination therapy is not a barrier to its prescription and provision. ${ }^{, 5} \mathrm{It}$ is unfortunate that this message is not followed by most purchasing authorities.

G R Foster consultant hepatologist

Liver Centre, Imperial College School of Medicine at St Mary's, St Mary's Hospital, London W2 1PG g.foster@ic.ac.uk

R Chapman consultant gastroenterologist Department of Gastroenterology, John Radcliffe Infirmary, Oxford OX3 9DU

On behalf of C Change

C Change includes most of the major charities representing patients with or at risk from hepatitis C (the British Liver Trust, the Haemophilia Society, Mainliners) as well as individual patients, clinicians, and pharmaceutical companies manufacturing therapeutics for hepatitis $\mathrm{C}$.

Competing interests: Dr Foster has been reimbursed for consultancy work and presentations at conferences by manufacturers of drugs used to treat hepatitis C. Dr Chapman has no competing interests.

1 Sallie R, King R, Silva E, Tibbs C, Johnson P, Williams R Community prevalence of hepatitis $\mathrm{C}$ viraemia: a polymerase chain reaction study. I Med Virol 1994:43:111-4.

2 Tong M, El-Farrah N, Reikes A, Co R. Clinical outcomes after transfusion associated hepatitis C virus. $N$ Engl J Med 1995:332:1463-6.

3 Panel C. EASL international consensus conference on hepatitis C-consensus statement. J Hepatol 1999;30:956-61. 4 Poynard T, Marcellin P, Lee SS, Niederau C, Minuk GS, Ideo $\mathrm{G}$, et al. Randomised trial of interferon alpha2b plus ribavirin for 48 weeks or for 24 weeks versus interferon alpha2b plus placebo for 48 weeks for treatment of chronic infection with hepatitis $\mathrm{C}$ virus. International Hepatitis Interventional Therapy Group (IHIT). Lancet 1998;352:1426-32.

5 House of Commons official report (Hansard) 2000;345(58): $137-8 \mathrm{WH}$.

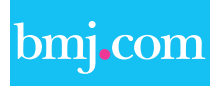

\section{Rapid responses}

Correspondence submitted electronically

is available on our website 